\section{OPEN ACCESS}

Edited by:

Armin Saalmueller,

University of Veterinary Medicine

Vienna, Austria

Reviewed by:

Tobias Kaeser,

North Carolina State University,

United States

Friederike Ebner

Free University of Berlin, Germany

*Correspondence:

Martin Matejovic matejovic@fnplzen.cz

Specialty section:

This article was submitted to

Comparative Immunology,

a section of the journal

Frontiers in Immunology

Received: 24 June 2019

Accepted: 17 January 2020

Published: 07 February 2020

Citation:

Horak J, Nalos L, Martinkova V, Tegl V,

Vistejnova L, Kuncova J,

Kohoutova M, Jarkovska $D$,

Dolejsova M, Benes J, Stengl M and

Matejovic M (2020) Evaluation of

Mesenchymal Stem Cell Therapy for

Sepsis: A Randomized Controlled

Porcine Study.

Front. Immunol. 11:126.

doi: 10.3389/fimmu.2020.00126

\title{
Evaluation of Mesenchymal Stem Cell Therapy for Sepsis: A Randomized Controlled Porcine Study
}

\author{
Jan Horak ${ }^{1,2}$, Lukas Nalos ${ }^{2,3}$, Vendula Martinkova ${ }^{2,4}$, Vaclav Tegl ${ }^{2,5}$, Lucie Vistejnova ${ }^{2,6}$, \\ Jitka Kuncova ${ }^{2,3}$, Michaela Kohoutova ${ }^{2,3}$, Dagmar Jarkovska $^{2,3}$, Martina Dolejsova $^{2}$, \\ Jan Benes ${ }^{2,5}$, Milan Stengl ${ }^{2,3}$ and Martin Matejovic ${ }^{1,2 *}$
}

${ }^{1}$ First Medical Department, Faculty of Medicine in Pilsen, Charles University, Pilsen, Czechia, ${ }^{2}$ Faculty of Medicine in Pilsen, Biomedical Center, Charles University, Pilsen, Czechia, ${ }^{3}$ Department of Physiology, Faculty of Medicine in Pilsen, Charles University, Pilsen, Czechia, ${ }^{4}$ Third Department of Surgery, University Hospital Motol and First Medical School, Charles University, Prague, Czechia, ${ }^{5}$ Department of Anesthesia and Intensive Care Medicine, Faculty of Medicine in Pilsen, Charles University, Pilsen, Czechia, ${ }^{6}$ Department of Histology and Embryology, Faculty of Medicine in Pilsen, Charles University, Pilsen, Czechia

Background: Treatment with mesenchymal stem cells (MSCs) has elicited considerable interest as an adjunctive therapy in sepsis. However, the encouraging effects of experiments with MSC in rodents have not been adequately studied in large-animal models with better relevance to human sepsis.

Objectives: Here, we aimed to assess safety and efficacy of bone marrow-derived MSCs in a clinically relevant porcine model of progressive peritonitis-induced sepsis.

Methods: Thirty-two anesthetized, mechanically ventilated, and instrumented pigs were randomly assigned into four groups ( $n=8$ per group): (1) sham-operated group (CONTROL); (2) sham-operated group treated with MSCs (MSC-CONTROL); (3) sepsis group with standard supportive care (SEPSIS); and (4) sepsis group treated with MSCs (MSC-SEPSIS). Peritoneal sepsis was induced by inoculating cultivated autologous feces. MSCs $\left(1 \times 10^{6} / \mathrm{kg}\right)$ were administered intravenously at $6 \mathrm{~h}$ after sepsis induction.

Results: Before, 12, 18, and $24 \mathrm{~h}$ after the induction of peritonitis, we measured systemic, regional, and microvascular hemodynamics, multiple-organ functions, mitochondrial energy metabolism, systemic immune-inflammatory response, and oxidative stress. Administration of MSCs in the MSC-CONTROL group did not elicit any measurable acute effects. Treatment of septic animals with MSCs failed to mitigate sepsis-induced hemodynamic alterations or the gradual rise in Sepsis-related organ failure assessment scores. MSCs did not confer any protection against sepsis-mediated cellular myocardial depression and mitochondrial dysfunction. MSCs also failed to modulate the deregulated immune-inflammatory response. 
Conclusion: Intravenous administration of bone marrow-derived MSCs to healthy animals was well-tolerated. However, in this large-animal, clinically relevant peritonitis-induced sepsis model, MSCs were not capable of reversing any of the sepsis-induced disturbances in multiple biological, organ, and cellular systems.

Keywords: sepsis, septic shock, acute organ dysfunction, mesenchymal stem cells, cell therapy, immunomodulation

\section{INTRODUCTION}

The lack of effective therapy for sepsis remains a major unmet medical need. Even though substantial progress has been made in understanding the underlying pathophysiology of sepsis, translation of these advances into clinically effective therapies has been disappointing. Given the extreme complexity of sepsis pathogenesis, the paradigm "one disease, one drug" is obviously flawed and combinations of multiple targets that involve early immunomodulation and cellular protection are needed. The immunomodulatory, anti-inflammatory, anti-apoptotic, metabolomic, and anti-microbial effects of mesenchymal stem cells (MSCs) may have scientific and clinical relevance in this context (1). Indeed, application of MSCs in preclinical models of sepsis has been associated with lower mortality, improved course of sepsis due to inhibition of pro-active elements of the immune system, and a change in the pro- and anti-cytokine ratio both in vitro and in vivo (1-3). In addition, no preclinical study published so far has demonstrated adverse effects associated with the application of MSCs in animal models of sepsis. It must be emphasized, however, that these encouraging results were largely derived from rodent models with clearly limited relevance to human sepsis. Hence, a thorough investigation of the effects of MSCs in clinically relevant large-animal models is urgently needed before translation to the clinical field. Therefore, we conducted a randomized controlled experimental study to explore the biological effects of MSCs on the background of standard care in comparison to standard conservative therapy in a porcine model of peritonitis-induced progressive sepsis. The model fulfills recently defined requirements for preclinical sepsis studies (4). We aimed to examine both the safety of MSCs in healthy animals and the effect of MSCs on various biological systems related to multiple pathophysiological pathways during sepsis progression.

\section{MATERIALS AND METHODS}

\section{Mesenchymal Stem Cells}

Allogenic porcine MSCs were isolated from healthy pigs. Bone marrow from the tibia or femur bones was aspirated

Abbreviations: ALT, Alanine aminotransferase; AST, Aspartate aminotransferase; CVP, Central venous pressure; $\mathrm{DO}_{2}$, Systemic oxygen delivery; EDTA, Ethylenediaminetetraacetic acid; hsTnT, High-sensitivity troponin T; IL-6, Interleukin 6; IL-8, Interleukin 8; IL-10, Interleukin 10; MAP, Mean arterial pressure; MSCs, Mesenchymal stem cells; PAOP, Pulmonary artery occlusion pressure; $\mathrm{PaO}_{2} / \mathrm{FiO}_{2}$, Oxygenation index; PBS, Phosphate-buffered saline; SOFA, Sepsis-related organ failure assessment; TNF- $\alpha$, Tumor necrosis factor $\alpha$; $\mathrm{VO}_{2}$, Systemic oxygen uptake. into 50-mL tubes (Techno Plastic Products-TPP, Trasadingen, Switzerland) containing heparin (B Braun) by puncture with a sterile needle. MSCs were isolated from bone marrow by gradient centrifugation $(440 \times g, 30 \mathrm{~min})$ on Ficoll-Paque Plus (GE Healthcare, North Richland Hills, Texas, USA). The layer of mononucleated cells was washed with phosphatebuffered saline (PBS) and plated in a $75-\mathrm{cm}^{2}$ culture flask (TPP) containing $\alpha$-MEM cell culture medium (Thermo Fisher Scientific, Waltham, MA, USA) supplemented with $10 \%$ fetal bovine serum (Thermo Fisher Scientific), $1 \mathrm{mM} \mathrm{L-}$ glutamine (Biochrom, Cambridge, UK), $6.0 \mathrm{mg} / \mathrm{mL}$ penicillin/10 $\mathrm{mg} / \mathrm{mL}$ streptomycin (Biosera, Nuaille, France), and 0.25 $\mathrm{mg} / \mathrm{mL}$ gentamicin (Biosera). Culture medium was changed every second day. After 10 days, MSCs were harvested by ethylenediaminetetraacetic acid (EDTA)/trypsin $1 \times$ (Biosera) and separated into three $75-\mathrm{cm}^{2}$ culture flasks (TPP). Culture medium was changed again every second day, and after 10 days, MSCs were harvested by EDTA/trypsin $1 \times$ (Biosera) and cryopreserved in liquid nitrogen $\left(1 \times 10^{6}\right.$ cells/cryotube). Four weeks before transplantation, MSCs were thawed, plated in $150-\mathrm{cm}^{2}$ flasks (TPP) containing $20 \mathrm{~mL}$ of the culture medium described above, and cultured for 4 weeks to obtain about $5 \times 10^{7}$ cells with one passage cycle. In this way, the stem cell properties of MSCs were maintained. On the day of transplantation, MSCs were harvested as described above, counted, re-suspended in $100 \mathrm{~mL}$ of saline solution (B Braun) pre-warmed to $37^{\circ} \mathrm{C}\left(10^{6} / \mathrm{kg}\right.$ of pig weight $)$ per pig, and immediately administered through the central venous line $6 \mathrm{~h}$ after induction of peritonitis. Before transplantation, the stem cell phenotype of MSCs was evaluated by flow cytometric detection of CD90, CD73, and CD44 markers (shown in Supplemental Digital Material). MSCs were washed with PBS and stained with $5 \mu \mathrm{L}$ of APC-CD90 (Biolegend, San Diego, CA, USA), PE-CD73 (Biolegend), BV421-CD44 (Biolegend), and FITC-CD45 (Bio-Rad, Hercules, CA, USA) for $15 \mathrm{~min}$ in the dark at room temperature. Afterwards, MSCs were washed and resuspened in $300 \mu \mathrm{L}$ of PBS followed by measurement on a BD FACS Aria Fusion cell analyzer (Becton Dickinson, Franklin Lakes, NJ, USA). Post-acquisition analysis of data was performed using FlowJo software (FlowJo LLC, Ashland, OR, USA). The ability of transplanted MSCs to differentiate was evaluated by their formation of adipo-, osteo-, and chondrolineages. MSCs were seeded into 12-well-cultivation dishes (TPP) with a seeding density of $3.8 \times 10^{4}$ cells/well for adipogenic and chondrogenic differentiation, and $1.9 \times 10^{4}$ cells/well for osteogenic differentiation in culture medium. After a 24-h attachment period, the medium was discarded and replaced with 


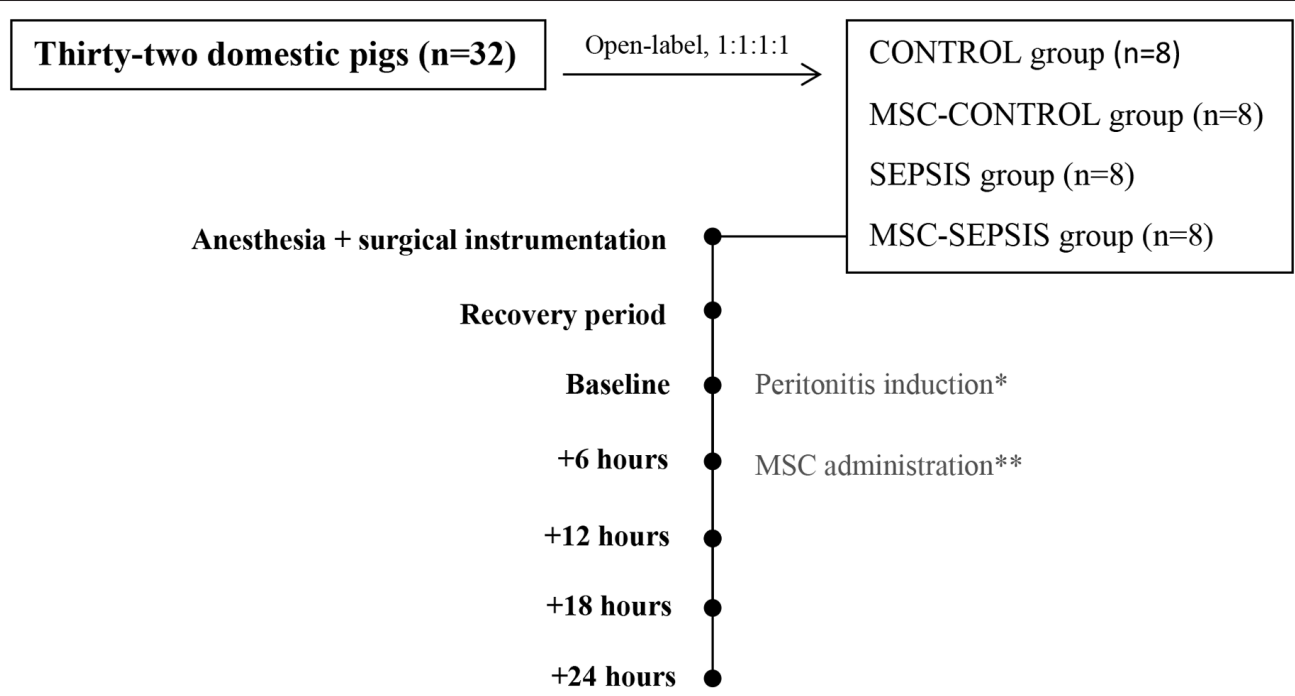

FIGURE 1 | Basic scheme of experimental protocol. The $\left(^{\star}\right)$ stands for peritonitis induction in septic groups (SEPSIS and MSC-SEPSIS). The (**) stands for MSCs administration in treated groups (MSC-CONTROL and MSC-SEPSIS).

$3 \mathrm{~mL}$ of StemPro ${ }^{\circledR}$ Adipogenesis Differentiation Kit, StemPro ${ }^{\circledR}$ Chondrogenesis Differentiation Kit, or StemPro ${ }^{\circledR}$ Osteogenesis Differentiation Kit (all Thermo Fisher Scientific) for adipogenic, chondrogenic, or osteogenic differentiation, respectively. After a differentiation period of 21 days, the cells were stained with oil red $\mathrm{O}$ for lipid droplet visualization in adipogenesis, alcian blue for glycoprotein visualization in chondrogenesis, and alizarin red S (all Sigma Aldrich, St. Louis, MO, USA) for calcium ion visualization in osteogenesis. Donor MSCs were not matched with recipients.

\section{Animals}

All experiments were performed in adherence to the European Directive for the Protection of Vertebrate Animals Used for Experimental and Other Scientific Purposes (86/609/EU). The protocols were approved by the Committee for Experiments on Animals of the Faculty of Medicine, Charles University, in Pilsen and by the Ministry of Education, Youth and Sports of the Czech Republic (protocol no. MSMT-20064/2015-3). All experiments were performed in the Laboratory of Experimental Intensive Care Medicine of the Biomedical Center at the Faculty of Medicine in Pilsen. Thirty-two domestic pigs (breed Black Pied Prestice Pig) from conventional breeding facility (ZD Mladotice, Czech Republic) of either sex with a median weight of 43.5 (40-46) kg were used.

\section{Experimental Protocol}

The animals were assigned to one of four experimental groups (at a ratio of 1:1:1:1): sham-operated control group (CONTROL, $n=8$ ), control group treated with MSCs (MSC-CONTROL, $n$ $=8$ ), sham-operated sepsis group (SEPSIS, $n=8$ ), and septic group treated with MSCs (MSC-SEPSIS, $n=8$ ). The intervention was open-labeled. In septic animals, peritonitis was induced by inoculating $1 \mathrm{~g} / \mathrm{kg}$ of autologous feces (collected preoperatively and suspended in $200 \mathrm{~mL}$ of isotonic saline at $38^{\circ} \mathrm{C}$ ) into the abdominal cavity followed by a 6 -h recovery period (baseline). When sepsis-associated hypotension developed, fluid boluses (10 $\mathrm{ml} / \mathrm{kg}$ of Ringerfundin solution) were administered in a goal-directed manner guided by filling pressures and cardiac output response as part of hemodynamic resuscitation. Fluid resuscitation was discontinued if there was no further increase in cardiac output ( $10 \%$ threshold) and/or when the pulmonary artery occlusion pressure (PAOP) reached more than $15 \mathrm{mmHg}$. Continuous infusion of norepinephrine was administered if the mean arterial pressure (MAP) fell below $65 \mathrm{mmHg}$ and no further positive hemodynamic response was elicited via fluid resuscitation. Norepinephrine was titrated to maintain MAP between 65 and $70 \mathrm{mmHg}$. In MSC-CONTROL and MSCSEPSIS groups, MCSs were infused in a clinically relevant dose $\left(1 \times 10^{6} / \mathrm{kg}\right)$ over $10 \mathrm{~min}$ via the central venous line $6 \mathrm{~h}$ from the baseline. The MSC dose was chosen on the basis of several previous clinical $(5,6)$ as well as experimental rodent $(1,2)$ and large animal studies (7). At the end of the experiment, the animals were euthanized by anesthetic overdose and excision of the heart. Experimental protocol scheme is shown in Figure 1.

\section{Anesthesia and Surgical Instrumentation}

All animals were anesthetized with xylazine $(1 \mathrm{mg} / \mathrm{kg})$ and tiletamin-zolazepam ( $5 \mathrm{mg} / \mathrm{kg}$ ). A $2 \mathrm{mg} / \mathrm{kg}$ dose of $2 \%$ propofol was administered after intravenous line insertion. Animals were intubated and mechanically ventilated as follows: volume control mode with tidal volume of $8-10 \mathrm{~mL} / \mathrm{kg}$, positive end-expiratory pressure of $0.6 \mathrm{kPa}, \mathrm{FiO}_{2}$ of 0.3 , and respiratory rate adjusted to maintain arterial normocapnia. During surgery, anesthesia was maintained by continuous administration of $2 \%$ propofol (4-6 $\mathrm{mg} / \mathrm{kg} / \mathrm{h})$, fentanyl $(8-10 \mu \mathrm{g} / \mathrm{kg} / \mathrm{h})$, and rocuronium (2 $\mathrm{mg} / \mathrm{kg} / \mathrm{h}$ ). Drug dosing was halved after surgery. Continuous infusion of Ringerfundin solution (B-Braun Melsungen AG, 
Melsungen, Germany) was used as a fluid replacement at a dose of $10 \mathrm{~mL} / \mathrm{kg} / \mathrm{h}$ during surgery and $7 \mathrm{~mL} / \mathrm{kg} / \mathrm{h}$ thereafter. Continuous infusion of $10 \%$ glucose served to maintain arterial blood normoglycemia.

Before the surgical procedure, an arterial catheter was placed in the femoral artery for continuous invasive blood pressure monitoring and blood sampling. Pulmonary artery and central venous catheters were introduced via external jugular veins under ultrasound guidance. Midline laparotomy was performed and a pre-calibrated ultrasound flow probe (Transonic Systems, Ithaca, NY, USA) was placed around the left renal artery. Double-lumen ileostomy was constructed to assess gut mucosal microcirculation. Peritoneal drainage was inserted and epicystostomy was performed prior to abdominal wall closure. A recovery period of $6 \mathrm{~h}$ followed the surgical procedures.

\section{Monitoring, Sampling, and Measurements}

Data sets were recorded at baseline/sepsis induction, +12 , +18 , and $+24 \mathrm{~h}$ after peritonitis induction. Measurements and calculations included the assessment of systemic and regional hemodynamics (see Supplemental Digital Material),
A LYMPHOCYTES + MONOCYTES
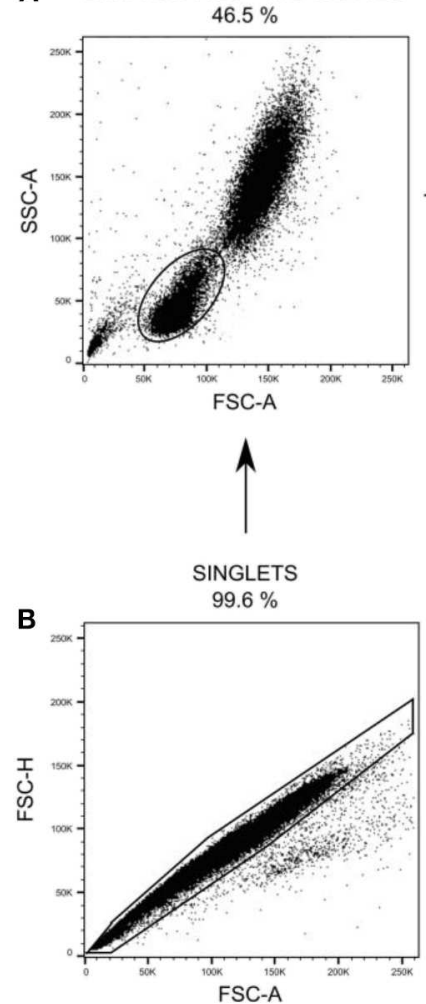

$\downarrow$

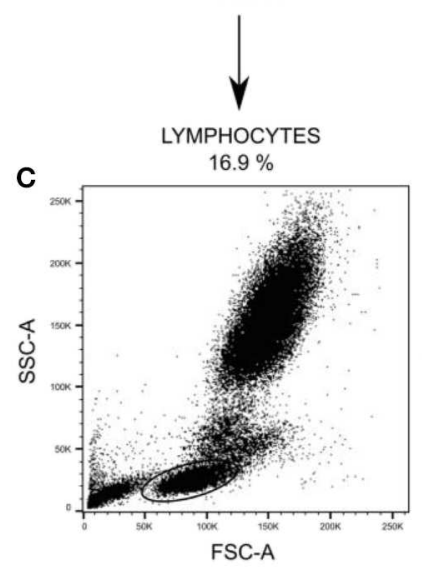

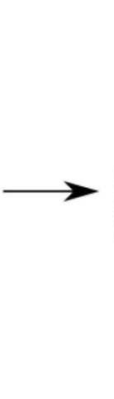

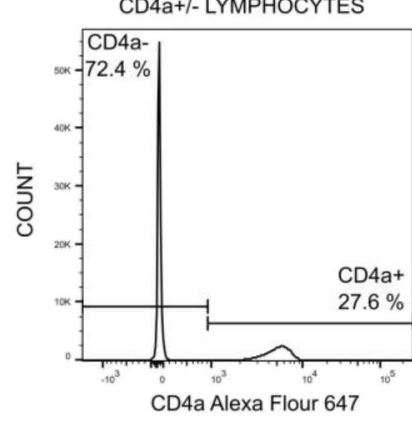

CD14+ MONOCYTES

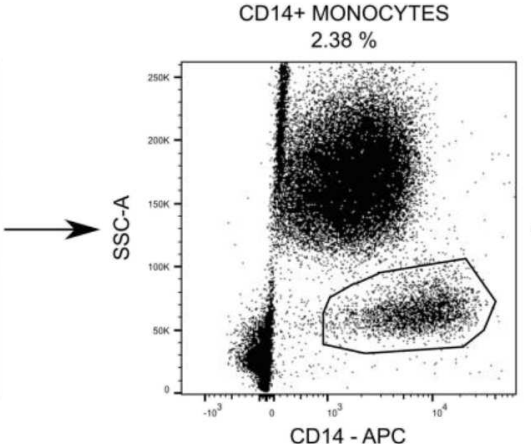

CD14 - APC
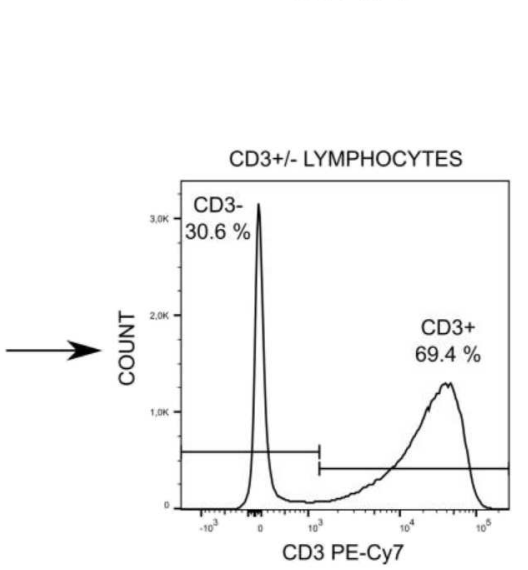
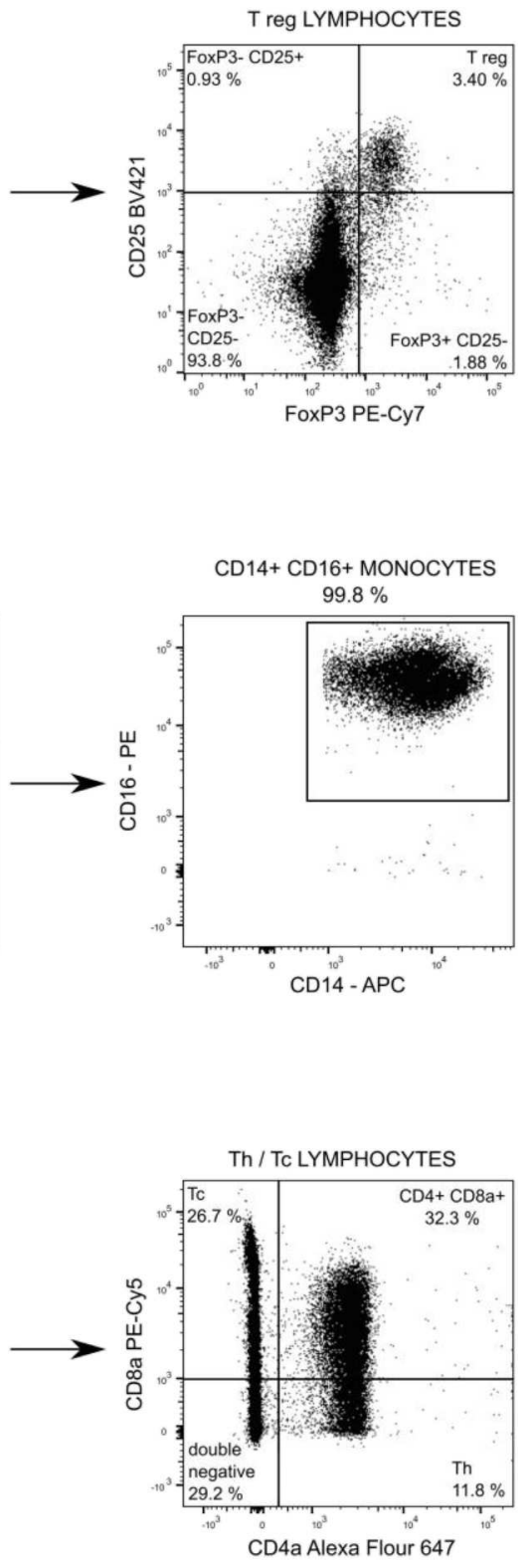

FIGURE 2 | Particular subpopulations of leukocytes were gated from singlets populations followed by gating on FSC and SSC (A,C) and followed by gating on specific T regulatory (T reg) lymphocytes (A), on CD14+ CD16+ monocytes (B), and on T-helper (Th) lymphocytes and cytotoxic (Tc) + CD8 $\alpha+\gamma \delta T$ lymphocytes (C) 
fluids, and vasopressor requirement. Arterial blood samples were analyzed for lactate, arterial and mixed venous blood gases, $\mathrm{pH}$, base excess by using POCT analyzer (Cobas B 123, Roche, Diagnostics, USA). Complete blood count and other biochemical analyses included serum creatinine, aspartate aminotransferase (AST), alanine aminotransferase (ALT), highsensitivity troponin I (hsTnI), albumin, and total protein were performed as described previously (8). Cytokines, including IL-6, IL-8, IL-10, and tumor necrosis factor $\alpha$ (TNF- $\alpha$ ), as well as C-reactive protein were analyzed by using the ELISA method (Porcine Quantikine ELISA Kit, R\&D System, Minneapolis, USA). Oxidative stress biomarker 8-isoprostane analysis was performed by using EIA porcine kit (Cayman Chemical, Michigan, USA). In addition, basic hemodynamics and acid-base balance parameters were measured prior to MSC's administration (i.e., $+6 \mathrm{~h}$, data not shown) to capture sepsis development.

The modified sepsis-related organ failure assessment (SOFA) score was determined according to the Third international consensus definitions for sepsis and septic shock (9) with exclusion of the Glasgow coma scale-based neurologic component. Gut mucosal microcirculation was recorded at each time point using a MicroScan handheld video microscope (MicroVision Medical, Amsterdam, Netherlands). Each record was split into three parts to visualize different areas of the gut mucosa and analyzed by Automated Vascular Analysis software version 4.0 (MicroVision Medical).
Cardiac myocytes were isolated from the left ventricle by enzymatic dissociation with collagenase A (Sigma-Aldrich) as previously reported (8). Sarcomeric contractions of isolated cardiac myocytes were measured with the HyperSwitch Myocyte Calcium and Contractility System (IonOptix LLC, Westwood, MA, USA), with the Sarclen sarcomere length acquisition module. Measurements were performed in normal Tyrode solution at $37 \pm 0.5^{\circ} \mathrm{C}$. Cells were stimulated with the MyoPacer Field Stimulator (IonOptix LLC) at cycles of 300, 500, 1,000, and 2,000 ms. IonWizard 6.5 software (IonOptix LLC) was used for offline analysis.

Cardiac mitochondrial function was assessed using highresolution respirometry (oxygraph Oroboros O2k; Oroboros Instruments, Innsbruck, Austria). Mitochondrial oxygen consumption was measured in permeabilized left ventricular samples at $37^{\circ} \mathrm{C}$. Transmural sample $\left(\sim 1 \mathrm{~cm}^{3}\right)$ was dissected from the proximal free wall of the left ventricle and cut into $2 \mathrm{mg}$ tissue samples that were quickly transferred into ice-cold biopsy preserving solution (BIOPS: $10 \mathrm{mM}$ Ca-EGTA buffer, $0.1 \mu \mathrm{M}$ free calcium, $20 \mathrm{mM}$ imidazole, $20 \mathrm{mM}$ taurine, $50 \mathrm{mM}$ K-MES, 0.5 mM DTT, $6.56 \mathrm{mM} \mathrm{MgCl2,} 5.77 \mathrm{mM}$ ATP, $15 \mathrm{mM}$ phosphocreatine, $\mathrm{pH}$ 7.1) with saponin $(50 \mu \mathrm{g} / \mathrm{ml})$, shaken gently on ice for $30 \mathrm{~min}$, washed in mitochondrial respiration

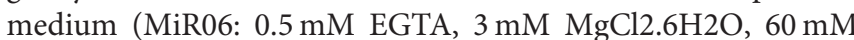
lactobionic acid, $20 \mathrm{mM}$ taurine, $10 \mathrm{mM} \mathrm{KH2PO} 4,20 \mathrm{mM}$ HEPES, $110 \mathrm{mM}$ D-sucrose, $1 \mathrm{~g} / \mathrm{l}$ albumin essentially fatty acid free, and $280 \mathrm{u} / \mathrm{ml}$ catalase) for $10 \mathrm{~min}$ and then placed into
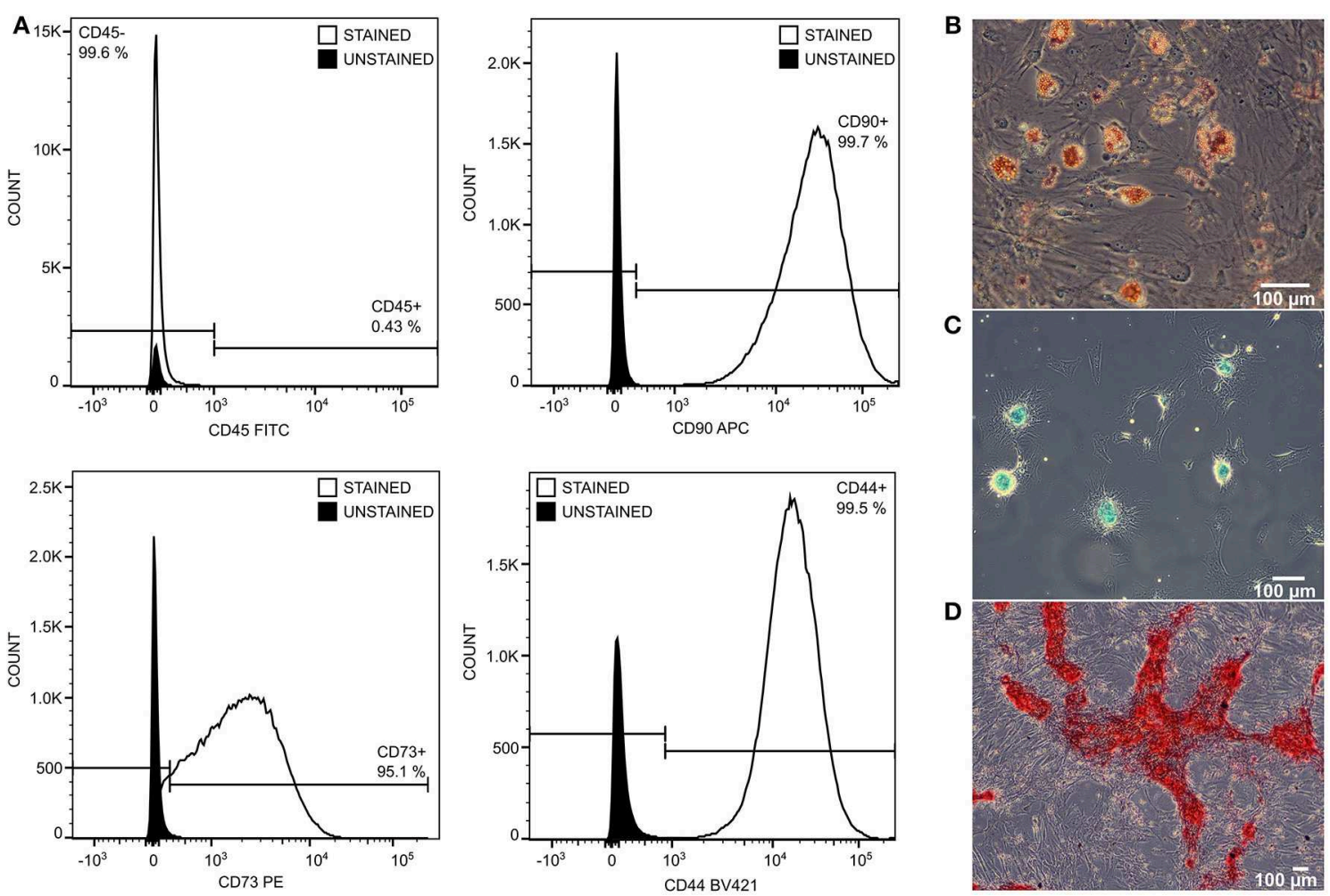

FIGURE 3 | The quality of transplanted MSCs was monitored by expression of stem cell surface markers and by differentiation ability. MSCs were negative to CD45 and positive to CD90, CD73, and CD44 (A). They differentiate into adipo- (B), chondro- (C), and osteo- (D) lineage in 21 days of differentiation protocol. 
oxygraph chambers. In the titration protocol, several substrates and inhibitors of the mitochondrial respiratory system were sequentially added into the chambers to determine particular respiratory states and activities of mitochondrial respiratory complexes. Oxygen consumption was analyzed online by DatLab software (Oroboros Instruments) as the negative time derivative of oxygen concentration in the chamber.

\section{Flow Cytometry of Leukocytes Subpopulations}

Changes in leukocytes subpopulations were monitored by flow cytometry. One hundred microliter of EDTA treated blood was stained for $15 \mathrm{~min}$ in dark and room temperature by cocktail of anti-CD specific antibodies (Table antibodies, Supplemental Digital Material) at baseline, 12 and $18 \mathrm{~h}$ after peritonitis induction ( $24 \mathrm{~h}$ was not measured due to operational reasons). Afterward staining, all samples were lysed by BD FACS Lysing Solution (Becton Dickinson, San Jose, USA) to separate leukocytes and contaminating erythrocytes. CD14posCD16pos monocytes, T-helper (Th) and cytotoxic T (Tc) $+\mathrm{CD} 8 \alpha+$ $\gamma \delta \mathrm{T}$ lymphocytes were washed by PBS, pelleted $(300 \times$ g, $5 \mathrm{~min}$ ) and re-suspened in $300 \mu \mathrm{l}$ of PBS followed by measurement. $\mathrm{T}$ regulatory (Treg) lymphocytes were fixed and permeabilized by FoxP3 staining buffer set (Thermo Fisher Scientific), washed by PBS, pelleted $(300 \times \mathrm{g}, 5 \mathrm{~min})$ and resuspened in $300 \mu \mathrm{l}$ of PBS followed by measurement. The measurement was performed by the BD FACS Aria Fusion cell analyzer (Becton Dickinson). One million events was acquired and the post-acquisition analysis of data was performed using FlowJo software (Becton Dickinson). The gating strategy for each subpopulation is summarized in Figure 2. Absolute counts of particular subpopulations were determined from total leukocytes counts acquired within standard biochemical analysis of blood samples.

\section{Statistical Analysis}

Statistical analysis was carried out using SigmaStat software version 3.5 (Systat Software Inc., Erkrath, Germany). Results are presented as median (interquartile range, range). Statistical comparisons were made using non-parametric statistics. Differences within each group before and after induction of sepsis were tested using Friedman ANOVA on ranks and, subsequently, Dunn's test for multiple comparisons. The Mann-Whitney rank sum test was performed to compare data between treatment groups (CONTROL vs. MSCCONTROL; SEPSIS vs. MSC-SEPSIS). A $p<0.05$ was regarded as statistically significant.

\section{RESULTS}

Administrated MSCs achieved standard quality as determined by the expression of stem cell markers $\mathrm{CD} 90^{+}, \mathrm{CD}^{+} 3^{+}, \mathrm{CD} 44^{+}$, $\mathrm{CD}_{4} 5^{-}$, and by their ability to differentiate into adipo-, chondro-, and osteo-lineages (Figure 3).

Five experiments were repeated due to perioperative death $(n=2)$ or premature death before baseline data collection or treatment commencement $(n=3)$. Data from animals that
TABLE 1 | Parameters describing organ function and systemic inflammation in sham-operated animals with and without MSC administration.

\begin{tabular}{|c|c|c|c|}
\hline Parameter & Timepoint & CONTROL & MSC-CONTROL \\
\hline \multirow[t]{4}{*}{ Urea (mmol/L) } & Baseline & $5(4.2-5.5)$ & $5.7(5-6.6)$ \\
\hline & $+12 \mathrm{H}$ & $5.5(3.6-5.9)$ & $6.1(5.1-7.3)^{\star}$ \\
\hline & $+18 \mathrm{H}$ & $5(3.3-5.6)$ & $5.5(4.5-6.6)$ \\
\hline & $+24 \mathrm{H}$ & $4.4(3.2-4.6)$ & $4.7(3.8-5.8)^{\star}$ \\
\hline \multirow{4}{*}{$\begin{array}{l}\text { Creatinine } \\
(\mu \mathrm{mol} / \mathrm{L})\end{array}$} & Baseline & $95(80-103)$ & $99(87-110)$ \\
\hline & $+12 \mathrm{H}$ & $93(77-108)$ & $100(88-107)$ \\
\hline & $+18 \mathrm{H}$ & $88(77-102)$ & $95(86-102)$ \\
\hline & $+24 \mathrm{H}$ & 85 (68-93) & 89 (83-103) \\
\hline \multirow[t]{4}{*}{ AST ( $\mu$ kat/L) } & Baseline & $0.7(0.6-1.5)$ & $0.8(0.6-1.9)$ \\
\hline & $+12 \mathrm{H}$ & $0.8(0.7-1.4)$ & $0.9(0.8-1.1)$ \\
\hline & $+18 \mathrm{H}$ & $0.8(0.7-1.6)$ & $1.0(0.9-1.5)$ \\
\hline & $+24 \mathrm{H}$ & $0.8(0.7-1.4)$ & $1.0(0.9-1.4)$ \\
\hline \multirow[t]{4}{*}{ ALT ( $\mu$ kat/L) } & Baseline & $0.5(0.5-0.7)$ & $0.6(0.5-0.7)$ \\
\hline & $+12 \mathrm{H}$ & $0.5(0.5-0.6)$ & $0.5(0.48-0.51)^{*}$ \\
\hline & $+18 \mathrm{H}$ & $0.5(0.4-0.6)$ & $0.5(0.47-0.50)^{*}$ \\
\hline & $+24 \mathrm{H}$ & $0.5(0.4-0.5)^{\star}$ & $0.52(0.5-0.5)^{\star}$ \\
\hline \multirow{4}{*}{$\begin{array}{l}\text { Trombocytes } \\
\left(1 \times 10^{9} / \text { L) }\right.\end{array}$} & Baseline & $285(226-315)$ & $260(231-357)$ \\
\hline & $+12 \mathrm{H}$ & $227(204-302)$ & $200(191-236)^{\star}$ \\
\hline & $+18 \mathrm{H}$ & $236(213-271)$ & $201(164-220)^{\star}$ \\
\hline & $+24 \mathrm{H}$ & $241(216-252)$ & $194(190-226)^{\star}$ \\
\hline \multirow{4}{*}{$\begin{array}{l}\mathrm{PaO}_{2} / \mathrm{FiO}_{2} \\
(\mathrm{mmHg})\end{array}$} & Baseline & $459(410-510)$ & $450(441-466)$ \\
\hline & $+12 \mathrm{H}$ & 408 (399-460) & $452(410-455)$ \\
\hline & $+18 \mathrm{H}$ & $344(262-404)^{\star}$ & $355(327-414)^{\star}$ \\
\hline & $+24 \mathrm{H}$ & $272(232-353)^{\star}$ & $313(187-412)^{\star}$ \\
\hline \multirow[t]{4}{*}{ hsTnT (ng/L) } & Baseline & $7.2(6.2-18.1)$ & $9.7(7.4-36.3)$ \\
\hline & $+12 \mathrm{H}$ & $7.7(6.7-21.6)$ & $9.2(7.6-24.8)$ \\
\hline & $+18 \mathrm{H}$ & $6.1(5.6-17.4)^{\star}$ & $9(7.1-19.9)$ \\
\hline & $+24 \mathrm{H}$ & $5.9(4.5-17.8)^{\star}$ & $10.5(6.6-18.7)$ \\
\hline \multirow[t]{4}{*}{ IL-6 (ng/L) } & Baseline & 47 (36-75) & $59(47-114)$ \\
\hline & $+12 \mathrm{H}$ & 48 (30-63) & $38(16-64)$ \\
\hline & $+18 \mathrm{H}$ & $64(48-212)$ & $61(33-66)$ \\
\hline & $+24 \mathrm{H}$ & $\begin{array}{c}352 \\
(139-1,451)^{\star}\end{array}$ & 175 (35-768) \\
\hline \multirow[t]{4}{*}{ TNF- $\alpha$ (ng/L) } & Baseline & $\begin{array}{c}91.3 \\
(77.7-123.2)\end{array}$ & $\begin{array}{c}100.3 \\
(62.1-145.1)\end{array}$ \\
\hline & $+12 \mathrm{H}$ & $58.9(54.2-89.5)$ & $52.7(38.8-75.8)^{\star}$ \\
\hline & $+18 \mathrm{H}$ & $60.0(53.4-68.5)$ & $59.3(50.7-88.9)^{\star}$ \\
\hline & $+24 \mathrm{H}$ & $\begin{array}{c}76.5 \\
(61.5-119.3)\end{array}$ & $94.2(57.4-112.2$ \\
\hline \multirow{4}{*}{$\begin{array}{l}\text { 8-Isoprostane } \\
(\mu \mathrm{g} / \mathrm{L})\end{array}$} & Baseline & $32.0(4.9-55.8)$ & $43.3(23.0-93.2)$ \\
\hline & $+12 \mathrm{H}$ & $8.4(6.7-28.5)$ & $23.5(11.6-31.3)$ \\
\hline & $+18 \mathrm{H}$ & $5.7(4.9-14.1)$ & $15.1(4.0-37.1)$ \\
\hline & $+24 \mathrm{H}$ & $6.7(4-72.3)$ & $55.6(14.1-89.4)$ \\
\hline
\end{tabular}

AST, aspartate aminotransferase; $A L T$, alanine aminotransferase; $\mathrm{PaO}_{2} / \mathrm{FiO}_{2}$, oxygenation index; hsTnT, high-sensitivity troponin T; IL-6, interleukin 6; TNF- $\alpha$, tumor necrosis factor $\alpha .{ }^{*} p<0.05$ between baseline and time-point. No statistical significance was found between groups. 

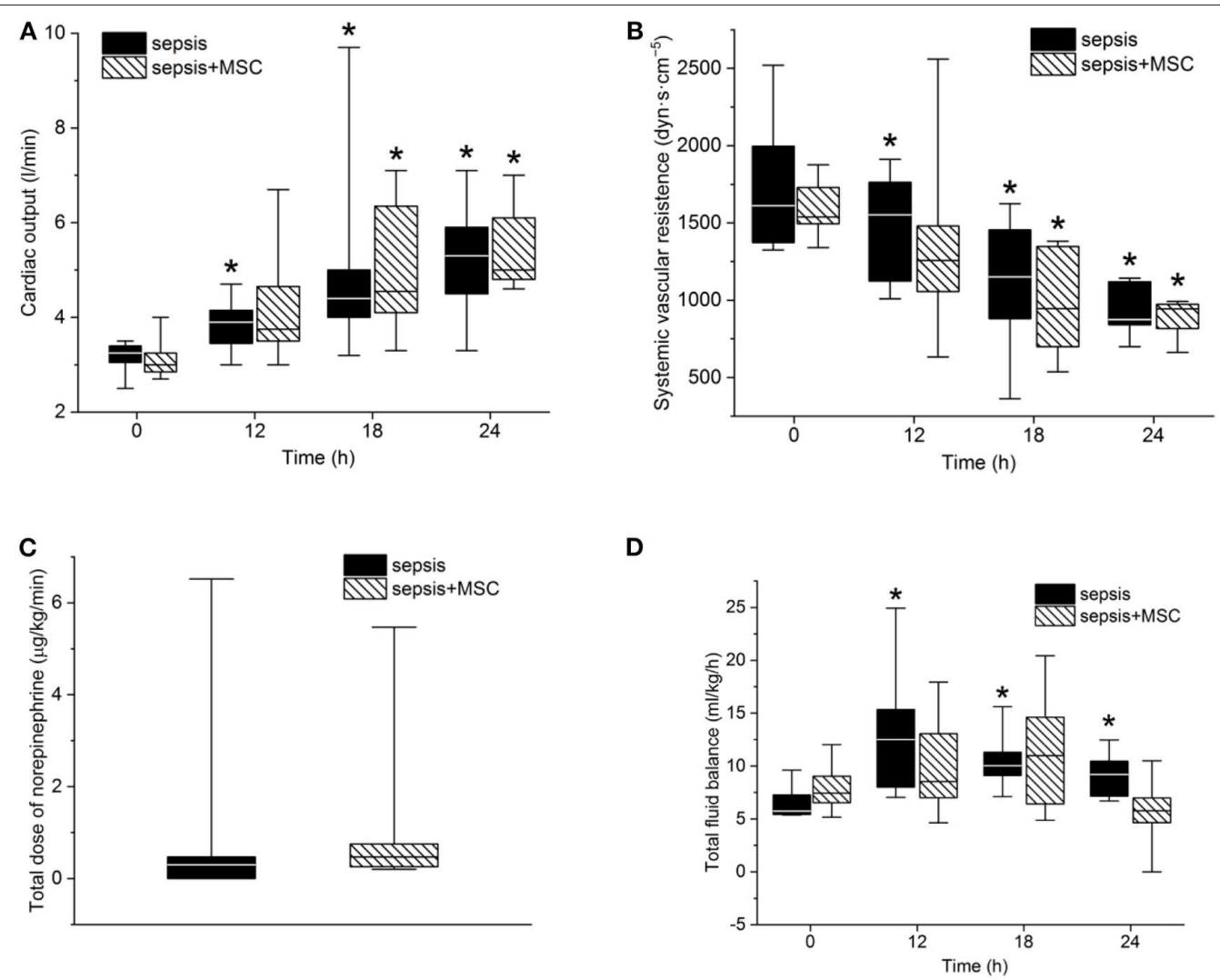

FIGURE 4 | (A) Cardiac output, systemic vascular resistance (B), total dose of norepinephrine (C) and total fluid balance (D). The $\left({ }^{*}\right)$ stands for significant difference in time $(p<0.05$ vs. baseline).

died prematurely were not used for analysis. Administration of MSCs to sham-operated healthy animals did not induce any significant alterations in systemic, regional, or microvascular hemodynamics (data not shown). Similarly, neither target organ functions nor markers reflecting inflammatory status and oxidative stress were affected by MSCs (Table 1).

All animals in both septic groups developed sepsis according to SEPSIS-3 criteria. Seven animals in the sepsis group and six animals in the MSC-SEPSIS group completed the whole 24-h protocol. Three animals $(n=1$ in sepsis, $n=2$ in MSC-SEPSIS group) died prematurely due to refractory septic shock. At the start of treatment (i.e., $6 \mathrm{~h}$ after induction of peritonitis) there were no statistically significant differences in any measured variables between SEPSIS and MSC-SEPSIS groups (data not shown).

After the induction of peritonitis, all pigs developed hyperdynamic sepsis with an increased cardiac output and reduced systemic vascular resistance, without intergroup differences (Figures 4A,B). Six pigs (75\%) in the sepsis group and eight pigs (100\%) in the MSC-SEPSIS group required vasopressor support to maintain MAP above $65 \mathrm{mmHg}$. The total dose of norepinephrine was comparable in both septic groups (Figure 4C) as was the time to the first administration of norepinephrine $[1,093(885-1,165) \mathrm{min}$ in SEPSIS vs. 748 (594944 ) $\mathrm{min}$ in MSC-SEPSIS group; $p=0.345]$. Likewise, there were no significant differences in the amount of fluid administered for hemodynamic resuscitation (Figure 4D). Other hemodynamic and metabolic variables are summarized in Table 2.

The modified SOFA score progressively increased in both septic groups. Treatment with MSCs failed to attenuate sepsisinduced organ dysfunction. The tendency of the SOFA score to increase was even more pronounced in the MSC-SEPSIS group, mainly as a result of earlier initiation of norepinephrine administration (Figure 5A). Indeed, no sign of a beneficial effect of MSCs was observed even when single organ systems included in SOFA score (i.e., lungs, kidneys, liver, platelets) were evaluated separately (single organ data not presented).

Peritonitis-induced sepsis resulted in gradually increased plasma levels of TNF- $\alpha$ and IL-6, providing evidence of a progressive systemic inflammatory response (Figures 5B,C). Treatment with MSCs did not result in a favorable effect on any of these variables. Plasma levels of IL-10 remained under the detection limit in all animals. Levels of $\mathrm{CD}_{1} 4^{+} \mathrm{CD} 16^{+}$ monocytes, and $\mathrm{Th}$, Tc $+\mathrm{CD} 8 \alpha+\gamma \delta \mathrm{T}$ lymphocytes, and $\mathrm{T}_{\text {reg }}$ lymphocytes decreased in time due to sepsis in both experimental groups. The CD3+CD4a-CD8a+CD8b+gating consistently provided lower cell numbers than the CD3+CD4aCD8a+gating $[50-70 \%$, e.g., $69 \%(34 \%, 63 \%)$ in sepsis baseline, $62 \%(36 \%, 66 \%)$ in $18 \mathrm{~h}$ sepsis vs. $48 \%(36 \%$, $64 \%)$ in sepsis+MSC baseline, $60 \%(42 \%, 63 \%)$ in $18 \mathrm{~h}$ 
TABLE 2 | Hemodynamic and metabolic variables in septic animals with and without MSC administration.

\begin{tabular}{|c|c|c|c|}
\hline Parameter & TP & SEPSIS & MSC-SEPSIS \\
\hline \multirow[t]{4}{*}{ MAP (mmHg) } & Baseline & $73(68-81)$ & $70(64-74)$ \\
\hline & $+12 \mathrm{H}$ & $80(70-87)$ & $69(66-75)$ \\
\hline & $+18 \mathrm{H}$ & $71(64-71)$ & 68 (64-73) \\
\hline & $+24 \mathrm{H}$ & 72 (69-73) & 72 (68-75) \\
\hline \multirow[t]{4}{*}{ PAOP (mmHg) } & Baseline & $9(8-9)$ & $9(6-10)$ \\
\hline & $+12 \mathrm{H}$ & $11(8-11)$ & $8(6-10)$ \\
\hline & $+18 \mathrm{H}$ & $11(10-13)$ & $8(7-10)$ \\
\hline & $+24 \mathrm{H}$ & $10(9-12)$ & $9(8-11)$ \\
\hline \multirow[t]{4}{*}{ CVP (mmHg) } & Baseline & $8(8-10)$ & $7(7-9)$ \\
\hline & $+12 \mathrm{H}$ & $11(10-12)^{\star}$ & $9(8-12)$ \\
\hline & $+18 \mathrm{H}$ & $12(10-14)^{\star}$ & $10(8-14)^{\star}$ \\
\hline & $+24 \mathrm{H}$ & $11(10-15)^{\star}$ & $12(10-14)^{\star}$ \\
\hline \multirow[t]{4}{*}{$\mathrm{DO}_{2}(\mathrm{~mL} / \mathrm{min} / \mathrm{kg})$} & Baseline & $10.2(9.1-11.0)$ & $10.2(9.0-10.7)$ \\
\hline & $+12 \mathrm{H}$ & $12.2(11.2-15.3)$ & $14.4(12.7-16.2)$ \\
\hline & $+18 \mathrm{H}$ & $15.1(12.4-17.9)$ & $16.6(14.8-19.5)$ \\
\hline & $+24 \mathrm{H}$ & $16.7(14.9-21.0)^{\star}$ & $20.5(18.7-26.5)^{\star}$ \\
\hline \multirow[t]{4}{*}{$\mathrm{VO}_{2}(\mathrm{~mL} / \mathrm{min} / \mathrm{kg})$} & Baseline & $5.3(4.5-5.6)$ & $5.1(4.7-5.6)$ \\
\hline & $+12 \mathrm{H}$ & $5.7(4.9-6.4)$ & $6.0(5.4-6.8)$ \\
\hline & $+18 \mathrm{H}$ & 5.7 (5.3-6.3) & $6.7(5.6-7.7)$ \\
\hline & $+24 \mathrm{H}$ & $6.1(5.7-6.4)$ & $6.8(6.6-8.1)^{\star}$ \\
\hline \multirow[t]{4}{*}{ RBF/CO (\%) } & Baseline & $6.7(5.5-10.5)$ & $6.2(5.4-7.5)$ \\
\hline & $+12 \mathrm{H}$ & $5.3(3.5-6.3)^{*}$ & $4.0(2.2-5.0)$ \\
\hline & $+18 \mathrm{H}$ & $4.6(2.9-5.6)^{\star}$ & $2.2(0.9-4.1)^{\star}$ \\
\hline & $+24 \mathrm{H}$ & $3.7(2.1-5.4)^{\star}$ & $3.0(2.2-3.7)^{\star}$ \\
\hline \multirow{4}{*}{$\begin{array}{l}\text { Total vessel density (gut } \\
\text { mucosa) }\left(\mathrm{mm} / \mathrm{mm}^{2}\right)\end{array}$} & Baseline & $16.0(14.5-22.9)^{\#}$ & $26.6(22.6-28.7)^{\#}$ \\
\hline & $+12 \mathrm{H}$ & $22.2(13.1-24.2)$ & $20.2(16.0-32.8)$ \\
\hline & $+18 \mathrm{H}$ & 21.4 (16.6-26.0) & $19.4(17.6-22.2)$ \\
\hline & $+24 \mathrm{H}$ & $17.4(12.0-27.6)$ & $17.7(15.1-23.6)$ \\
\hline \multirow{4}{*}{$\begin{array}{l}\text { Perfused vessel density } \\
\text { (gut mucosa) } \\
\left(\mathrm{mm} / \mathrm{mm}^{2}\right)\end{array}$} & Baseline & 15.9 (14.5-22.9) & $26.6(18.7-28.7)$ \\
\hline & $+12 \mathrm{H}$ & 16.8 (12.5-20.3) & $20.1(16.0-31.6)$ \\
\hline & $+18 \mathrm{H}$ & $20.6(15.7-26.0)$ & 18.3 (16.5-20.8) \\
\hline & $+24 \mathrm{H}$ & $17.4(11.8-27.6)$ & $16.9(15.1-22.1)$ \\
\hline \multirow{4}{*}{$\begin{array}{l}\text { Arterial base excess } \\
(\mathrm{mmol} / \mathrm{L})\end{array}$} & Baseline & $4.9(3.6-5.7)$ & $4.0(2.8-5.2)$ \\
\hline & $+12 \mathrm{H}$ & $0.8(-0.2-1.7)^{\star}$ & $0.2(-0.9-1.5)$ \\
\hline & $+18 \mathrm{H}$ & $-0.1(-1.6-1.7)^{\star}$ & $-0.6(-9.8-0.1)^{\star}$ \\
\hline & $+24 \mathrm{H}$ & $-1.5(-2.7-2.4)^{\star}$ & $-1.7(-3.4-1.0)^{\star}$ \\
\hline \multirow[t]{4}{*}{ Arterial lactate $(\mathrm{mmol} / \mathrm{L})$} & Baseline & $1.1(1.0-1.2)$ & $1.1(1-1.2)$ \\
\hline & $+12 \mathrm{H}$ & $1.1(1.0-1.2)$ & $1(1-1.1)$ \\
\hline & $+18 \mathrm{H}$ & $1.2(1.1-1.3)$ & $1.3(1-5.5)$ \\
\hline & $+24 \mathrm{H}$ & $1.5(1.0-2.4)$ & $1.5(1.3-1.8)$ \\
\hline \multirow[t]{4}{*}{ Hemoglobin (g/dL) } & Baseline & $10.1(9.7-11.1)$ & $9.9(8.9-10.5)$ \\
\hline & $+12 \mathrm{H}$ & $10.9(10.5-12.2)^{\star}$ & $11.6(10.4-12)^{\star}$ \\
\hline & $+18 \mathrm{H}$ & $11.2(10.8-12.4)^{\star}$ & $11.2(9.6-12.6)^{*}$ \\
\hline & $+24 \mathrm{H}$ & $11.9(10.5-12.4)^{\star}$ & $12.7(12.2-12.8)^{\star}$ \\
\hline
\end{tabular}

MAP, mean arterial pressure; PAOP, pulmonary artery occlusion pressure; CVP, central venous pressure; $D_{2}$, systemic oxygen delivery; $V_{2}$, systemic oxygen uptake; $R B F$, renal artery blood flow; CO, cardiac output. ${ }^{*} p<0.05$ between SEPSIS and MSC-SEPSIS group; * $p<0.05$ between time-point and baseline.
sepsis+MSC] suggesting a significant population of TCR $\gamma \delta$ cells. Importantly, the application of MSCs caused no significant differences when comparing SEPSIS and MSC-SEPSIS groups at each time point (Figure 6). Data on full blood count and other inflammatory parameters in sham-operated and septic animals with and without MSC administration are shown in Supplemental Digital Material (Tables 1, 2).

In isolated cardiac myocytes, sarcomeric contractions were decreased in septic cells at lower stimulation rates $(1,0.5 \mathrm{~Hz})$. Application of MSC did not exert any significant effect on sarcomeric contraction regardless whether in control (nonseptic; not shown) or septic cardiac myocytes (Figure 7A). Kinetic parameters of sarcomeric contractions (e.g., time to $50 \%$ of peak contraction, time to $50 \%$ relaxation) were not affected by sepsis nor by application of MSCs (not shown). Mitochondrial respiration was suppressed in septic hearts and this reduction was mainly due to inhibition of Complex II and IV. Application of MSCs, either in control (not shown) or septic animals, did not affect cardiac mitochondrial respiration (Figures 7B,C).

\section{DISCUSSION}

The present study was designed to evaluate the shortterm safety, tolerability, and efficacy of a single intravenous administration of bone marrow-derived MSCs in a large-animal, peritonitis-induced sepsis model. The model was characterized by the development of the full spectrum of sepsis-induced organ dysfunction with typical hemodynamic, metabolic, and inflammatory host response phenotypes. The main findings indicate that: (1) the application of MSCs to healthy animals was well-tolerated without any measurable acute effects on macroand microcirculatory hemodynamics, organ, and mitochondrial functions; (2) early treatment with MSCs failed to mitigate the development of sepsis-induced hemodynamic alterations including the progression of sepsis to septic shock; (3) MSCs did not confer any protection against alterations in cellular energy metabolism and multiple organ functions; and (4) treatment failed to counteract a gradual sepsis-driven systemic immuneinflammatory response.

The discrepancy between the salutary effects of MSCs reported in multiple preclinical models (10-15) and the apparent absence of any sign of improvement in multiple biological systems in this model is a striking and key finding of this study, deserving critical discussion. Many emerging treatment strategies shown to be effective in preclinical studies, generally failed to yield beneficial effects in clinical trials. Numerous arguments have been proposed to explain the failure to translate experimental results into effective treatments for human sepsis, including complexity and heterogeneity of sepsis, methodologically inappropriate clinical trials, and clinically irrelevant animal models $(4,16)$. The latter may prove particularly important in the context of our study. Most notably, all but one study published thus far have involved exclusively rodents, mainly mice $(1,2,7)$. The marked difference in the immune-inflammatory response to insults between rodents and humans is well-documented (17). Fundamental differences include, but are not limited to, 

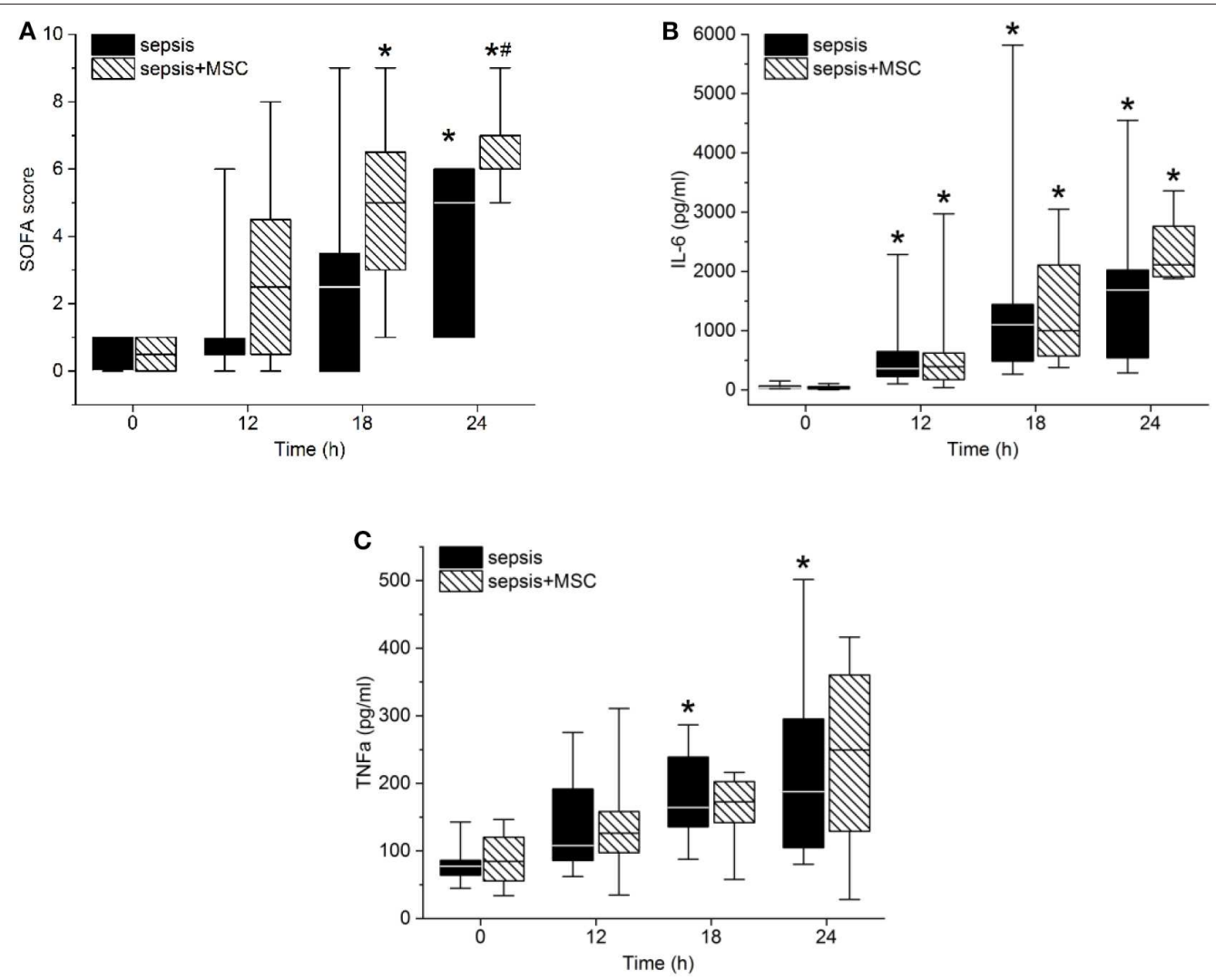

FIGURE 5 | Sepsis-related organ failure assessment (SOFA) score (A), Interleukin-6 (B), and TNF $\alpha$ serum levels (C). The (\#) stands for statistical significance between the groups $(p<0.05)$. The $\left(^{*}\right)$ stands for significant differences in time in particular groups $(p<0.05$ vs. baseline).

the divergence of the transcriptomic response, the mismatch of temporal response patterns, differences in both innate and adaptive immunity, and/or the homogeneity of highly inbred mouse strains (18). Pigs, on the other hand, show very similar endotoxin sensitivity and tissue antigenicity, similar cardiovascular and renal physiology including hyperdynamic circulation in sepsis and similar temporal response pattern to humans (19). Additional technical advantages are associated with bigger body size that is comparable to humans and allows extensive instrumentation, continuous monitoring, and serial blood sampling. Moreover, frequent use of specific pathogenfree (SPF) animals in sepsis research, where alterations of the gut microbiome may markedly alter the animal's immune and inflammatory functions and susceptibility to infection, may also contribute to the disconnect between animal studies showing promising drug development and failure to translate to humans. In an interesting recent study a more straightforward comparison of response to anesthesia and surgical trauma was made between conventional and SPF rats (20). Comparison between conventional and SPF animals within one species and even strain (Spraque-Dawley) revealed decreased tolerance to anesthesia, hemodynamic instability, aberrant hematology, traumatic bleeding, and reduced physiological reserve in SPF animals. This altered phenotype to the stress of surgical trauma was completely reversed when SPF animals were returned to the original conventional facility. The role of gut microbiota is another aspect worth consideration when discussing factors potentially affecting the host response to infectious stimulus. It has been demonstrated that variations in the gut microbiota of donor mice influenced clinical as well as molecular phenotype of sepsis (21). At the time of our study, we did not assess individual microbial composition of porcine feces. However, given the single provider of laboratory animals with identical environmental conditions and comparable individual hemodynamic, metabolic, and inflammatory responses to feces, we hypothesize that the putative role of inter-individual variations in fecal microbiota was rather limited in this experiment. Taken together, the genetic and physiological proximity of pigs and humans makes this species an excellent biomodel for translational research, and utilization of domestic (farm) pigs exposed to similar environmental pathogens as humans is clearly superior to mouse models, in which the SPF handling probably limits the clinical translatability even more fundamentally $(22,23)$.

Our results are also in sharp contrast with data from Laroye et al., who reported less profound alterations in systemic hemodynamics and, therefore, longer time to death in septic pigs treated with human umbilical cord-derived MSCs (7). Surprisingly, the hemodynamic improvement observed in the above study occurred despite the lack of clear evidence for significant effects of MSCs on inflammation, bacterial clearance, 

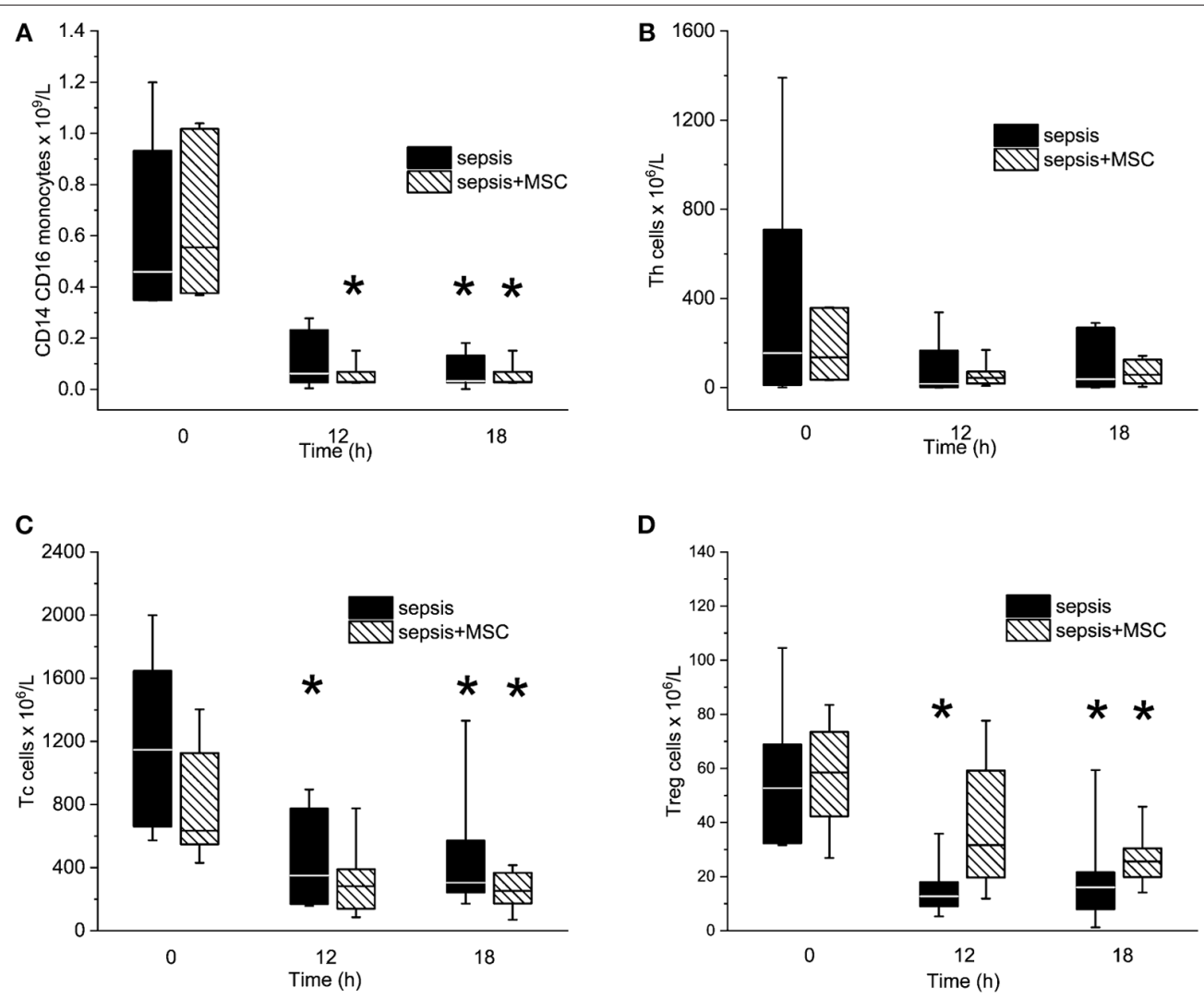

FIGURE 6 | The absolute numbers of CD14/CD16 pos monocytes (A), T helper lymphocytes (B), Tc + CD8 $\alpha+\gamma \delta$ T lymphocytes (C), and T regulatory lymphocytes (D). The $\left(^{*}\right)$ stands for significant difference between particular time point and baseline only $(p<0.05)$.

and a rather transient alleviation of lung and kidney function. Although the dose and timing of interventions with MSCs were comparable to those reported here, the two studies differed with respect to the source of MSCs. As the secretome of umbilical cord-derived MSCs used by Laroye et al. might differ from bone marrow-derived MSCs, it is possible that MSCs from different sources possess different immunomodulatory capacity $(24,25)$. Bone marrow-derived MSCs have not only been proven to be effective in several small-animal sepsis studies $(10,24,26)$, but they are currently the preferred source of MSCs in clinical settings and the only one with the ability to restore the original niche (27). Nevertheless, in a mouse model of endotoxin-induced sepsis, MSCs ameliorated sepsis-associated organ injury and mortality in spite of different MSC sources (26). Furthermore, the infectious burden and severity of sepsis were three times higher in Laroye's experiment compared to our study and the time course of pro-inflammatory cytokines, in particular TNF$\alpha$, markedly differed from our model, thus suggesting a different inflammatory environment. Whether these differences may have accounted for such discrepancy in results remains speculative.

Understanding existing methodological limitations and obstacles is essential for further translational research. Even though they were used successfully in previous experiments (28), we investigated the effects of one dose and one source of MSCs. Furthermore, MSCs were administered at a single time point. It would be of interest to evaluate the efficacy of MSCs obtained from different tissue sources, given in a dose-response fashion, and administered at different time points within the same experimental setting. The timing may be of critical importance for the interpretation of our results, because in the vast majority of positive preclinical studies, MSCs were administered very early, i.e., within $4 \mathrm{~h}$ after sepsis induction (2). No study has tested the application of MSCs beyond a 6-h time window (2). Indeed, the potential role of timing of the intervention has recently been demonstrated in a human endotoxemia model (29). In that study, intravenous infusion of allogenic human adipose MSCs exerted mixed time-dependent pro-inflammatory or anti-inflammatory and pro-coagulant effects (28). This suggested considerable biological complexity of MSCs and, possibly, a relatively narrow time frame for the treatment of early sepsis. Another relevant issue is the role of antibiotics in potentiating the action of MSCs. In a mouse model of sepsis induced by cecal ligation and puncture, combined treatment with MSCs and antibiotics greatly improved sepsis-associated symptoms and survival, indicating some synergistic effect (30). In our study, antibiotic therapy was not used. Our model was designed to create hyperdynamic sepsis, with increasing severity over time. Antibiotic therapy was expected to blunt the host response, thereby attenuating the development and full manifestation of a true clinical septic response during $24 \mathrm{~h}$, 

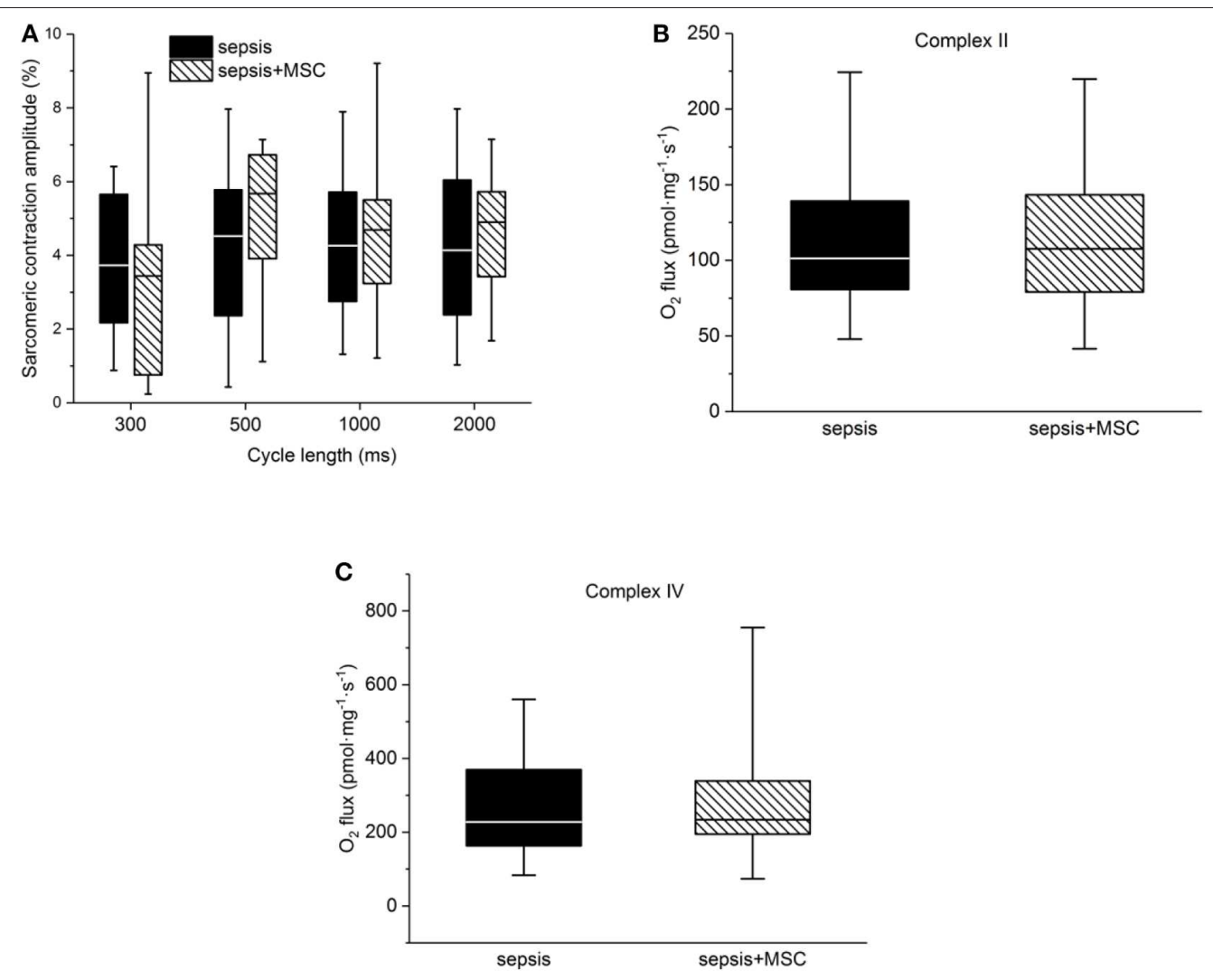

FIGURE 7 | Cellular myocardial depression. (A) Relative sarcomeric contraction amplitudes in cardiac myocytes from septic animals with or without application of MSC. (B) Mitochondrial respiration. Complex II-dependent oxygen consumption in septic myocardium without or with application of MSC. (C) Mitochondrial respiration. Complex IV-dependent oxygen consumption in septic myocardium without or with application of MSC.

which is what we instead sought to elicit in our experiment. Nevertheless, the interactions between antibiotic therapy and MSCs represent another important question warranting further investigation. We cannot exclude that the protective effect of MSCs might have manifested through other markers/pathways not monitored in our study. However, given that we assessed several clinically relevant and mutually independent biological targets, including macro- and microcirculatory perfusion, multiple organ functions, mitochondrial energy metabolism, systemic immune-inflammatory response, and oxidative stress, it seems unlikely that we would have missed major treatment effects.

The manufacturing of MSCs for this study was consistent with procedures applied elsewhere using fetal bovine serum for MSC propagation, trypsin for MSC harvesting, and a single freeze/thaw cycle for MSCs cryopreservation (10, 11, 15). Transplanted MSCs conformed to the criteria of the International Society for Cellular Therapy (31) and were kept for the minimum number of passages (up to four) to maintain their stem cell phenotype and avoid senescence (32). Paradoxically, the inconsistency in MSCs potency could lie in their sensitivity to a cytokine environment (33). As each pathology and even patient serum is accompanied by specific qualitative and quantitative cytokine composition, the immunomodulatory function of MSCs can be highly dependent on a particular patient's response to a specific pathology or treatment.

Another issue with possible role in MSCs potency is their matching to the recipient. There is the lack of studies comparing effects of matched vs. mismatched MSCs in the large animal model of sepsis. However, the clinical study of the team of GarciaSancho (34) showed that better HLA matching of donor MSCs with recipients did not enhance the efficacy of MSCs therapy in osteoarthritis and degenerative disc disease. Furthermore, there are several completed clinical trials applying allogenic MSC without any analysis of donor MSCs and recipient matching (5, 35-37) indicating that the donor MSCs and recipient matching may not play the role in MSCs potency. This direction is further supported by tendencies to apply pooled MSCs batches as better available and reproducible source of MSCs (38). However, upon the lack of available data comparing matched vs. mismatched MSCs therapy in sepsis relevant animal models we can only speculate about the role of this issue in MSCs efficacy in general.

Despite these limitations, our study benefits from a number of strengths and important findings. The history of sepsis research has repeatedly shown that no new therapeutic approach that was successfully tested in preclinical models was effective in clinical practice (39). Our model replicates many of the biological features intrinsic to human septic shock and 
integration of standard day-to-day care resuscitative measures makes it an appealing sepsis model in translational research. The International Society for Stem Cell Research has recently released guidelines for clinical translation stating strongly that large-animal models should be used for stem cell research and that any clinical trial should be preceded by compelling preclinical evidence obtained from these models (40). The clinical application of MSCs that we are witnessing in the field of orthopedics or neurology, and which is based on minimal evidence of benefit and safety, represents a path that critical care medicine should avoid (1). Generally homogenous and encouraging results attained by current preclinical testing cannot be considered as sufficient arguments for launching clinical trials, in part, due to a considerable risk that the effect of MSCs is overstated given that a number of studies with negative results have not been published.

\section{CONCLUSION}

In this large, clinically relevant animal peritonitis-induced sepsis model, MSCs were not capable of reversing any of the sepsisinduced disturbances in multiple biological, organ, and cellular systems. Collectively, our study cautions against the use of MSCs in a complex disease such as sepsis, as our understanding of the role MSCs play in it is still incomplete and unknown factors may influence the outcome.

\section{DATA AVAILABILITY STATEMENT}

The datasets generated for this study are available on request to the corresponding author.

\section{ETHICS STATEMENT}

The animal study was reviewed and approved by the Committee for Experiments on Animals of the Faculty of

\section{REFERENCES}

1. Horak J, Nalos L, Martinkova V, Benes J, Stengl M, Matejovic M. Mesenchymal stem cells in sepsis and associated organ dysfunction: a promising future or blind alley? Stem Cells Int. (2017) 2017:7304121. doi: 10.1155/2017/7304121

2. Lalu MM, Sullivan KJ, Mei SH, Moher D, Straus A, Fergusson DA, et al. Evaluating mesenchymal stem cell therapy for sepsis with preclinical meta-analyses prior to initiating a first-in-human trial. Elife. (2016) 5:e17850. doi: 10.7554/eLife.17850

3. Matthay MA, Pati S, Lee JW. Concise review: mesenchymal stem (stromal) cells: biology and preclinical evidence for therapeutic potential for organ dysfunction following trauma or sepsis. Stem Cells. (2017) 35:31624. doi: 10.1002/stem.2551

4. Osuchowski MF, Ayala A, Bahrami S, Bauer M, Boros M, Cavaillon JM, et al. Minimum quality threshold in pre-clinical sepsis studies (Mqtipss): an international expert consensus initiative for improvement of animal modeling in sepsis. Shock. (2018) 50:377-80. doi: 10.1097/SHK.00000000000 01212

5. McIntyre LA, Stewart DJ, Mei SHJ, Courtman D, Watpool I, Granton J, et al. Cellular immunotherapy for septic shock. A phase I clinical trial. Am J Resp Crit Care Med. (2018) 197:337-47. doi: 10.1164/rccm.201705-1006OC
Medicine, Charles University, in Pilsen and by the Ministry of Education, Youth and Sports of the Czech Republic (protocol no. MSMT-20064/2015-3).

\section{AUTHOR CONTRIBUTIONS}

JH, LN, VM, VT, and JB performed animal experiments. $\mathrm{MM}$ and $\mathrm{MS}$ conceived and designed the study. MM, MS, $\mathrm{LV}$, and $\mathrm{JH}$ performed data analysis. $\mathrm{MM}$ and $\mathrm{JH}$ drafted the manuscript. LV and MD performed MSC processing and flow cytometry measurements. JK and MK performed mitochondrial function measurement and data analysis. MS and DJ performed cardiac myocytes measurements and data analysis. All authors contributed to data interpretation, editing of the manuscript, and read and approved the final manuscript.

\section{FUNDING}

This work was supported by the Ministry of Health of the Czech Republic, grant no. 15-32801A, the Charles University Research Fund (project no. Q39), and project no. CZ.02.1.01/0.0/0.0/16_019/0000787 Fighting Infectious Diseases awarded by the MEYS CR, financed from EFRR. All rights reserved.

\section{ACKNOWLEDGMENTS}

Special thanks belongs to Iveta Zimova for her help with MSCs culture procedures.

\section{SUPPLEMENTARY MATERIAL}

The Supplementary Material for this article can be found online at: https://www.frontiersin.org/articles/10.3389/fimmu. 2020.00126/full\#supplementary-material
6. Schlosser K, Wang JP, Dos Santos C, Walley KR, Marshall J, Fergusson DA, et al. Effects of mesenchymal stem cell treatment on systemic cytokine levels in a phase 1 dose escalation safety trial of septic shock patients. Crit Care Med. (2019) 47:918-25. doi: 10.1097/CCM.0000000000003657

7. Laroye C, Lemarié J, Boufenzer A, Labroca P, Cunat L, Alauzet C, et al. Clinical-grade mesenchymal stem cells derived from umbilical cord improve septic shock in pigs. Intensive Care Med Exp. (2018) 6:24. doi: 10.1186/s40635-018-0194-1

8. Stengl M, Bartak F, Sykora R, Chvojka J, Benes J, Krouzecky A, et al. Reduced L-type calcium current in ventricular myocytes from pigs with hyperdynamic septic shock. Crit Care Med. (2010) 38:57987. doi: 10.1097/CCM.0b013e3181cb0f61

9. Singer M, Deutschman CS, Seymour C, Shankar-Hari M, Annane D, Bauer M, et al. The third international consensus definitions for sepsis and septic shock (Sepsis-3). JAMA. (2016) 315:801-10. doi: 10.1001/jama.2016.0287

10. Nemeth K, Leelahavanichkul A, Yuen PS, Mayer B, Parmelee A, Doi K, et al. Bone marrow stromal cells attenuate sepsis via prostaglandin $\mathrm{E}(2)$ dependent reprogramming of host macrophages to increase their interleukin10 production. Nat Med. (2009) 15:42-9. doi: 10.1038/nm.1905

11. Mei SH, Haitsma JJ, Dos Santos CC, Deng Y, Lai PF, Slutsky AS, et al. Mesenchymal stem cells reduce inflammation while enhancing bacterial 
clearance and improving survival in sepsis. Am J Respir Crit Care Med. (2010) 182:1047-57. doi: 10.1164/rccm.201001-0010OC

12. Gupta N, Krasnodembskaya A, Kapetanaki M, Mouded M, Tan X, Serikov V, et al. Mesenchymal stem cells enhance survival and bacterial clearance in murine Escherichia coli pneumonia. Thorax. (2012) 67:5339. doi: 10.1136/thoraxjnl-2011-201176

13. Sung PH, Chang CL, Tsai TH, Chang LT, Leu S, Chen YL, et al. Apoptotic adipose-derived mesenchymal stem cell therapy protects against lung and kidney injury in sepsis syndrome caused by cecal ligation puncture in rats. Stem Cell Res Ther. (2013) 4:15. doi: 10.1186/scrt385

14. Devaney J, Horie S, Masterson C, Elliman S, Barry F, O’Brien T, et al. Human mesenchymal stromal cells decrease the severity of acute lung injury. Thorax. (2015) 70:625-35. doi: 10.1136/thoraxjnl-2015-206813

15. Krasnodembskaya A, Samarani G, Song Y, Zhuo H, Su X, Lee JW, et al. Human mesenchymal stem cells reduce mortality and bacteremia in gramnegative sepsis in mice in part by enhancing the phagocytic activity of blood monocytes. Am J Physiol Lung Cell Mol Physiol. (2012) 302:L100313. doi: 10.1152/ajplung.00180.2011

16. Perner A, Gordon AC, Angus DC, Lamontagne F, Machado F, Russell JA, et al. The intensive care medicine research agenda on septic shock. Intensive Care Med. (2017) 43:1294-305. doi: 10.1007/s00134-017-4821-1

17. Seok J, Warren HS, Cuenca AG, Mindrinos MN, Baker HV, Xu $\mathrm{W}$, et al. Genomic responses in mouse models poorly mimic human inflammatory diseases. Proc Natl Acad Sci USA. (2013) 110:3507-12. doi: 10.1073/pnas.1222878110

18. Stortz JA, Raymond SL, Mira JC, Moldawer LL, Mohr AM, Efron PA. Murine models of sepsis and trauma: can we bridge the gap? ILAR J. (2017) 58:90105. doi: 10.1093/ilar/ilx007

19. Goldfarb RD, Dellinger RP, Parrillo JE. Porcine models of severe sepsis: emphasis on porcine peritonitis. Shock. (2005) 24 (Suppl 1):75-81. doi: 10.1097/01.shk.0000191337.01036.b7

20. Letson HL, Morris J, Biros E, Dobson GP. Conventional and specific-pathogen free rats respond differently to anesthesia and surgical trauma. Sci Rep. (2019) 9:9399. doi: 10.1038/s41598-019-45871-z

21. Hilbert T, Steinhagen F, Senzig S, Cramer N, Bekeredjian-Ding I, Parcina $\mathrm{M}$, et al. Vendor effects on murine gut microbiota influence experimental abdominal sepsis. J Surg Res. (2017) 211:126-36. doi: 10.1016/j.jss.2016. 12.008

22. Dobson GP, Letson HL, Biros E, Morris J. Specific pathogen-free (SPF) animal status as a variable in biomedical research: have we come full circle? EBioMed. (2019) 41:42-3. doi: 10.1016/j.ebiom.2019.02.038

23. Bendixen E. Animal models for translational proteomics. Prot Clin Appl. (2014) 8:637-9. doi: 10.1002/prca.201470054

24. Mattar P, Bieback K. Comparing the immunomodulatory properties of bone marrow, adipose tissue, and birth-associated tissue mesenchymal stromal cells. Front Immunol. (2015) 6:560. doi: 10.3389/fimmu.2015. 00560

25. Arutyunyan I, Elchaninov A, Makarov A, Fatkhudinov T. Umbilical cord as prospective source for mesenchymal stem cell-based therapy. Stem Cells Int. (2016) 2016:6901286. doi: 10.1155/2016/6901286

26. Ou H, Zhao S, Peng Y, Xiao X, Wang Q, Liu H, et al. Comparison of bone marrow tissue- and adipose tissue-derived mesenchymal stem cells in the treatment of sepsis in a murine model of lipopolysaccharideinduced sepsis. Mol Med Rep. (2016) 14:3862-70. doi: 10.3892/mmr.201 6.5694

27. Reinisch A, Etchart N, Thomas D, Hofmann NA, Fruehwirth M, Sinha S, et al. Epigenetic and in vivo comparison of diverse MSC sources reveals an endochondral signature for human hematopoietic niche formation. Blood. (2015) 125:249-60. doi: 10.1182/blood-2014-04-572255

28. Perlee D, van Vught LA, Scicluna BP, Maag A, Lutter R, Kemper EM, et al. Intravenous infusion of human adipose mesenchymal stem cells modifies the host response to lipopolysaccharide in humans: a randomized, single-blind, parallel group, placebo controlled trial. Stem Cells. (2018) 36:1778-88. doi: 10.1002/stem.2891

29. Marrazzo P, Crupi AN, Alviano F, Teodori L, Bonsi L. Exploring the roles of MSCs in infections: focus on bacterial diseases. J Mol Med. (2019) 97:43750. doi: 10.1007/s00109-019-01752-6

30. Alcayaga-Miranda F, Cuenca J, Martin A, Contreras L, Figueroa FE, Khoury M. Combination therapy of menstrual derived mesenchymal stem cells and antibiotics ameliorates survival in sepsis. Stem Cell Res Ther. (2015) 6:199. doi: 10.1186/s13287-015-0192-0

31. Dominici M, Le Blanc K, Mueller I, Slaper-Cortenbach I, Marini FC, Krause DS, et al. Minimal criteria for defining multipotent mesenchymal stromal cells. The International Society for Cellular Therapy position statement. Cytotherapy. (2016) 8:315-7. doi: 10.1080/14653240600855905

32. Martin I, De Boer J, Sensebe L, MSC Committee of the International Society for Cellular Therapy. A relativity concept in mesenchymal stromal cell manufacturing. Cytotherapy. (2016) 18:613-20. doi: 10.1016/j.jcyt.2016.02.004

33. Krampera M, Galipeau J, Shi Y, Tarte K, Sensebe L, MSC Committee of the International Society for Cellular Therapy. Immunological characterization of multipotent mesenchymal stromal cells; The International Society for Cellular Therapy (ISCT) working proposal. Cytotherapy. (2013) 15:105461. doi: 10.1016/j.jcyt.2013.02.010

34. Garcia-Sancho J, Sanchez A, Vega A, Noriega DC, Nocito M. Influence of HLA matching on the efficacy of allogeneic mesenchymal stromal cell therapies for osteoarthritis and degenerative disc disease. Transpl Dir. (2017) 3:e205. doi: 10.1097/TXD.0000000000000724

35. Vega A, Martin-Ferrero MA, Del Canto F, Alberca M, Garcia V, Munar A, et al. Treatment of knee osteoarthritis with allogeneic bone marrow mesenchymal stem cells: a randomized controlled trial. Transplantation. (2015) 99:168190. doi: 10.1097/TP.0000000000000678

36. Wilson JG, Liu KD, Zhuo H, Caballero L, McMillan M, Fang X, et al. Mesenchymal stem (stromal) cells for treatment of ARDS: a phase 1 clinical trial. Lancet. (2015) 3:24-32. doi: 10.1016/S2213-2600(14)70291-7

37. Hare JM, DiFede DL, Rieger AC, Florea V, Landin AM, El-Khorazaty J, et al. Randomized comparison of allogeneic versus autologous mesenchymal stem cells for nonischemic dilated cardiomyopathy: POSEIDON-DCM trial. J Am Coll Cardiol. (2017) 69:526-37. doi: 10.1016/j.jacc.2016.11.009

38. Widholz B, Tsitlakidis S, Reible B, Moghaddam A, Westhauser F. Pooling of patient-derived mesenchymal stromal cells reduces interindividual confounder-associated variation without negative impact on cell viability, proliferation and osteogenic differentiation. Cells. (2019) 8:E633. doi: 10.3390/cells8060633

39. Cohen J, Vincent JL, Adhikari NKJ, Machado FR, Angus DC, Calandra T, et al. Sepsis: a roadmap for future research. Lancet Infect Dis. (2015) 15:581-614. doi: 10.1016/S1473-3099(15)70112-X

40. Daley GQ, Hyun I, Apperley JF, Barker RA, Benvenisty N, Bredenoord $\mathrm{AL}$, et al. Setting global standards for stem cell research and clinical translation: The 2016 ISSCR Guidelines. Stem Cell Rep. (2016) 6:78797. doi: 10.1016/j.stemcr.2016.05.001

Conflict of Interest: The authors declare that the research was conducted in the absence of any commercial or financial relationships that could be construed as a potential conflict of interest.

Copyright (c) 2020 Horak, Nalos, Martinkova, Tegl, Vistejnova, Kuncova, Kohoutova, Jarkovska, Dolejsova, Benes, Stengl and Matejovic. This is an open-access article distributed under the terms of the Creative Commons Attribution License (CC BY). The use, distribution or reproduction in other forums is permitted, provided the original author(s) and the copyright owner(s) are credited and that the original publication in this journal is cited, in accordance with accepted academic practice. No use, distribution or reproduction is permitted which does not comply with these terms. 